\title{
PENERAPAN METODE PROBLEM BASED INSTRUCTION (PBI) UNTUK MENINGKATKAN HASIL BELAJAR PPKN SISWA KELAS IV DI SDN GALANG BULAN DESA JELANTIK KECAMATAN JONGGAT KABUPATEN LOMBOK TENGAH TAHUNPELAJARAN 2011-2012
}

\author{
Drs. Komang Sundara. \& Muh. Basri \\ (Dosen PNS Dpk. Kopertis Wilayah VIII)
}

INFO ARTIKEL
Riwayat Artikel:
Diterima: $07-09-2016$
Disetujui: $30-09-2016$

Kata Kunci:

Penerapan Metode PBI, Hasil Belajar.

\begin{abstract}
ABSTRAK
Abstrak: Salah satu langkah untuk memiliki kemampuan mengajar yang baik adalah harus menguasai teknik-teknik penyajian atau biasa disebut metode mengajar. Metode merupakan salah satu komponen dalam proses belajar mengajar yang berpengaruh terhadap pencapaian tujuan pembelajaran. Rumusan masalah dalam penelitian ini adalah apakah apakah dengan penerapan model Pembelajaran Problem Based Instruduction (PBI) dapat meningkatkan hasil belajar siswa kelas IV di SDN Galang Bulan Desa Jelantik Kec. Jonggat Kab. Lombok Tengah tahun pelajaran 2011-2012?. Tujuan dalam penelitian ini yaitu untuk mengetahui bagaimana penerapan model Pembelajaran Problem Based Instruduction (PBI) dalam meningkatkan hasil belajar siswa kelas IV di SDN Galang Bulan Desa Jelantik Kec. Jonggat Kab. Lombok Tengah tahun pelajaran 2011-2012.

Metode analisis data yang digunakan adalah analisis statistic dengan menggunakan rumus Uji treatment (t). yaitu $t=\frac{M d}{\sqrt{\frac{\sum X^{2} d}{N(N-1}}}$

Hasil penelitian menunjukkan bahwa penerapan model Pembelajaran Problem Based Instruduction (PBI) dapat meningkatkan hasil belajar siswa kelas IV di SDN Galang Bulan Desa Jelantik Kec. Jonggat Kab. Lombok Tengah tahun pelajaran 2011-2012.. Hal ini terbukti dari hasil perhitungan dengan menggunakan t-hitung diperoleh nilai sebesar 22, 97 langkah selanjutnya adalah membandingkan nilai tersebut dengan nilai $\mathrm{t}_{\text {tabel }}$ pada derajat kepercayaan $5 \%$ dan diperoleh hasil sebesar 2, 423 sehingga $t_{\text {hitung }}>t_{\text {tabel }} \quad(22,97>2$, 423).
\end{abstract}

\section{A. LATAR BELAKANG}

Peningkatan kualitas pembelajaran, dan efektivitas metode pembelajaran. Kurikulum harus komprehensif dan responsif terhadap dinamika sosial, relevan dan mampu mengakomodasikan keberagaman keperluan dan kemajuan teknologi. Kualitas pembelajaran harus ditingkatkan melalui pendekatan pembelajaran yang efektif di kelas, yang lebih memberdayakan potensi siswa.

Pendekatan kontekstual adalah suatu pendekatan pengajaran yang dari karakteristiknya memenuhi harapan itu, yaitu merupakan suatu konsep belajar dengan cara guru mengaitkan situasi dunia nyata siswa ke dalam kelas dan mendorong siswa membuat hubungan antara pengetahuan yang dimilikinya dengan penerapannya.

Dalam pembelajaran kontekstual terdapat tiga model pembelajaran bagi pendidik dalam rangka penerapannya. Salah satunya adalah model pembelajaran kooperatif (belajar melalui konteks komunikasi personal, pemakaian bersama dan sebagainya). Model pembelajaran kooperatif merupakan model pembelajaran yang akhir-akhir ini sangat populer, termasuk untuk bidang IPA. Beberapa ahli menyatakan bahwa model ini tidak hanya unggul dalam membantu siswa memahami konsep-konsep yang sulit, tetapi juga sangat berguna untuk menumbuhkan kerjasama, kemampuan membantu teman dan sebagainya Dominasi guru berceramah sudah sangat kurang dan telah beralih pada aktivitas membimbing dan memotivasi siswa. Sementara itu aktivitas siswa lebih banyak berupa bekerja, membaca, dan diskusi antar siswa (Sutardi $\mathrm{dkk}: 2001)$.

Pada pendidikan Kewarganegaraan yang berhasil akan membuahkan sikap mental yang cerdas, penuh rasa tanggung jawab dari peserta didik. Sikap ini disertai dengan perilaku yang beriman dan bertakwa kepada Tuhan Yang Maha Esa dan menghayati nilainilai falsafah bangsa, kedua berbudi, berbudi pekerti luhur, berdisiplin dalam masyarakat, berbangsa, bernegara, rasional, dinamis, dan sadar akan hak dan kewajiban sebagai warga negara, bersifat profesional, yang dijiwai oleh kesadaran bela negara, aktif 
52 CIVICUS I Pendidikan Pancasila dan Kewarganegaraan memanfaatkan ilmu pengetahuan dan teknologi serta seni untuk kepentingan kemanusiaan, bangsa dan negara. (Sumarsono S. Dkk: 2004: 6-7).

Salah satu langkah untuk memiliki kemampuan mengajar yang baik adalah harus menguasai teknikteknik penyajian atau biasa disebut metode mengajar. Metode merupakan salah satu komponen dalam proses belajar mengajar yang berpengaruh terhadap pencapaian tujuan pembelajaran. Metode tidak berdiri sendiri melainkan sangat berkaitan erat dengan komponen yang penting dalam keberhasilan belajar yaitu kesiapan siswa menerima pelajaran, guru yang mengajar sebelumnya, materi apa yang dipelajari sebelumnya, kesiapan guru dalam menyampaikan materi, ketersediaan sarana dan prasarana yang ada di sekolah karena semuanya itu menjadi pendukung utama keberhasilan kegiatan belajar mengajar.

Kurangnya daya serap siswa pada mata pelajaran Pendidikan Pancasila dan Kwarganegaraan disebabkan oleh tiga faktor yaitu

1. Penggunaan metode belajar yang masih belum mampu menyebabkan siswa semakin aktif dalam belajar seperti metode ceramah, metode tanya jawab dan metode diskusi.

2. Kurangnya fasilitas pendukung dalam pembelajaran seperti buku dan alat peraga.

3. Kurangnya motivasi belajar para siswa.

Mencermati hal tersebut di atas, sudah saatnya untuk diadakan pembaharuan, inovasi ataupun gerakan perubahan ke arah pencapaian tujuan pendidikan di atas. Pembelajaran PPKn hendaknya menggunakan metode yang bervariasi guna mengoptimalkan potensi siswa. Upaya-upaya guru dalam mengatur dan memberdayakan berbagai variabel pembelajaran merupakan bagian penting dalam keberhasilan siswa mencapai tujuan yang direncanakan.

Melihat kenyataan diatas, maka salah satu cara untuk mengatasi masalah tersebut adalah dengan menggunakan pembelajaran picture and picture merupakan suatu pembelajaran yang mengemukakan bahwa salah satu strategi yang digunakan tepat untuk memaparkan bagian-bagian dari pokok bahasan dengan baik serta untuk memahami konsep yang ada pada siswa adalah strategi atau metode pembelajaran problem based instruction sehingga aktivitas siswa semakin aktif.

Berdasarkan uraian di atas peneliti tertarik untuk mengadakan penelitian tentang penerapan model Pembelajaran Problem Based Instruduction (PBI) dapat meningkatkan hasil belajar siswa kelas IV di SDN Galang Bulan Desa Jelantik Kec. Jonggat Kab. Lombok Tengah tahun pelajaran 2012/2013.

\section{B. METODE PENELITIAN}

\section{RANCANGAN PENELITIAN}

Pendekatan/metode merupakan cara yang digunakan dalam penelitian yang berbentuk metode penelitian survey, deskripsi, eksperimen, naturalistic, policy research (penelitian polisi), action research (penelitian tindakan), evaluasi, sejarah (Ridwan,2005:10). Metode yang digunakan dalam penelitian ini adalah metode deskripsi kuantitatif yaitu metode penelitian yang menggunakan analisis statistik dalam manganalisa data-data hasil penelitian (Arikunto, 2006:86). Menurut Rahmat (2001:30), metode deskripsi kuantitatif adalah suatu metode penelitian yang dapat meluluskan secara sistematis fakta atau karakteristik
Vol. 4, No. 2, September 2016, hal 51-58

populasi tertentu atau bidang tertentu secara faktual dan cermat.

Rancangan penelitian adalah suatu pendekatan yang digunakan dalam suatu penelitian, dalam buku metodelogi penelitian dijelaskan: "Rancangan pada dasarnya merupakan keseluruhan proses pemikiran dan penentuan matang tentang hal yang dilakukan serta dapat pula dijadikan dasar penilaian baik oleh peneliti itu maupun orang lain terhadap peneliti, dan bertujuan memberikan pertanggung jawaban terhadap semua langkah yang diambil "(Suharsimi A, 2006:306).

Sehubungan dengan penelitian ini, maka rancangan penelitian menggunakan: "One-Group Exsperiment atau yang disebut dengan Treatment By Subject Designs" (Suharsimi, 2006:306). Penggunaan rancangan penelitian ini, karena diberikan kepada kelompok subjek yang sama sebagai group eksperimen sekaligus sebagai group control. Adapun secara konseptual rancangan penelitian tersebut dapat digambarkan sebagai berikut:

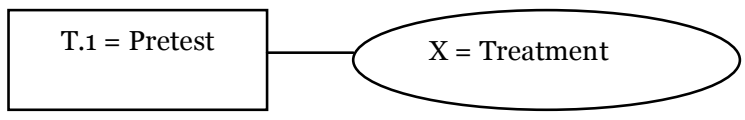

Gamabar 01: Rancangan Penelitian

Berdasarkan gambar tersebut di atas maka:

$\mathrm{T} .1$ = Pre test (tes awal) untuk mengetahui prestasi belajar sebelum pelaksanaan pembelajaran.

$\mathrm{X} \quad=$ Treatment (perlakuan) yakni pelaksanaan pembelajaran.

$\mathrm{T} .2$ = post test (tes akhir) untuk mengetahui prestasi belajar setelah pelaksanaan pembelajaran menggunakan metode pembelajaran.

Adapun prosedur pelaksanaan rancangan

tersebut adalah sebagai berikut :

1. Pelaksanaan test awal (pre-test/T1), untuk mengukur prestasi belajar sebelum diberikan perlakuan berupa pembelajaran.

2. Pemberian perlakuan pembelajaran dengan mengacu pada program pembelajaran yang sudah disisipkan.

3. Pelaksanaan test akhir (post-test/T2), untuk mengetahui hasil belajar siswa setelah pemberian metode pembelajaran.

\section{WAKTU PENELITIAN}

Adapun batas-batas lokasi sekolah sebagai sebagai berikut:

1. Sebelah Utara Jalan Raya

2. Sebelah Timur Rumah penduduk

3. Sebelah Selatan Rumah Penduduk

4. Sebelah Barat Rumah Penduduk

Adapun waktu pelaksanaan dari penelitian ini adalah mulai dari bulan Juni 2011 sampai dengan bulan Pebruari 2012.

\section{RUANG LINGKUP PENELITIAN}

Ruang lingkup dari penelitian ini adalah penelitian dilakukan di kelas IV dengan keadaaa siswa sebagai berikut:

Tabel 01.

Keadaan Siswa SDN Galang Bulan Tahun Pelajaran 2011- 2012

\begin{tabular}{|l|l|l|l|l|}
\hline No & Kelas & Laki & Perempuan & Jumlah \\
\hline
\end{tabular}




\begin{tabular}{|c|c|c|c|c|}
\hline $\mathbf{1}$ & $\mathbf{2}$ & $\mathbf{3}$ & $\mathbf{4}$ & $\mathbf{5}$ \\
\hline 1 & Kelas I & 12 & 14 & 26 \\
\hline 2 & Kelas II & 20 & 13 & 28 \\
\hline 3 & Kelas III & 18 & 20 & 28 \\
\hline 4 & Kelas IV & 10 & 18 & 30 \\
\hline 5 & Kelas V & 14 & 12 & 26 \\
\hline 6 & Kelas VI & 11 & 11 & 22 \\
\hline \multicolumn{2}{|c|}{ Jumlah } & 72 & 88 & 160 \\
\hline
\end{tabular}

Sumber : Dokumen, SDN Galang Bulan tahun 2011 .

Adapun yang akan dijadikan sebagai perbandingan untuk mengetahui prestasi belajar siswa kelas IV pada mata pelajaran PPKN sebelum dan sesudah diajarkan dengan menggunakan metode pembelajaran problem based instrution.

\section{KEADAAN RUANG DAN GEDUNG}

Keadaan Ruang Dan Gedung Sdn Galang Bulan Tahun 2011

\begin{tabular}{|r|l|c|l|l|}
\hline No & \multicolumn{1}{|c|}{ Jenis ruang } & Jml & Kondisi & Ket \\
\hline 1 & Ruang Kepala Sekolah & 1 & Baik & \\
\hline 2 & Ruang Guru & 1 & Baik & \\
\hline 3 & Ruang Kelas & 6 & Baik & \\
\hline 4 & Ruang Perpustakaan & 1 & Baik & \\
\hline 5 & Ruang Laboratorium & - & Baik & \\
\hline 7 & Ruang Tata Usaha & - & & \\
\hline 8 & Ruang Komputer & 1 & Baik & \\
\hline 9 & Ruang UKS & - & Baik & \\
\hline 10 & Mushalla & & Baik & \\
\hline 11 & Ruang Dapur Darurat & 1 & Baik & \\
\hline 12 & $\begin{array}{l}\text { Kamar Mandi/WC } \\
\text { Guru }\end{array}$ & 1 & Baik & \\
\hline 13 & $\begin{array}{l}\text { Kamar Mandi/WC } \\
\text { Siswa }\end{array}$ & 3 & Baik & \\
\hline 14 & Kantin & - & Baik & \\
\hline 15 & $\begin{array}{l}\text { Lapangan } \\
\text { Olahraga/upacara }\end{array}$ & 1 & Baik & \\
\hline 16 & Tempat Parkir & 1 & Baik & \\
\hline & Rumah Penjaga & 1 & Rusak & \\
\hline
\end{tabular}

Sumber Data : SDN Galang Bulan tahun 2011

Berdasarkan data tersebut maka secara keseluruhan kondisi bangunan baik dapat digolongkan semua dalam keadaan baik sehingga proses pembelajaran berjalan dengan baik sesuai dengan yang diharapkan. Di samping kondisi bangunan yang cukup bagus juga dilengkapi dengan sarana yang baik pula. Hal ini dapat dilihat pada keadaan sarana dan prasarana SDN Galang Bulan.

\section{Keadaan sarana dan prasarana}

Keadaan sarana dan prasarana SDN Galang Bulan tahun 2011-2012

\begin{tabular}{|r|l|l|l|}
\hline No & Jenis ruang & Kondisi & Jumlah \\
\hline 1 & Meja Guru & .Baik & 10 \\
\hline 2 & Kursi Guru & Baik & 12 \\
\hline 3 & Kursi tamu & Baik & 1 \\
\hline 4 & Meja murid & Baik & 115 \\
\hline 5 & $\begin{array}{l}\text { Bangku } \\
\text { murid }\end{array}$ & Baik & 230 \\
\hline 7 & Lemari & Baik & 6 \\
\hline 8 & Papan Tulis & Baik & 6 \\
\hline 9 & Papan Data & Baik & 6 \\
\hline 10 & Mesin TIk & Baik & 2 \\
\hline 11 & Mesin Hitung & Baik & 2 \\
\hline 12 & Komputer & Baik & 1 \\
\hline 13 & $\begin{array}{l}\text { Pengeras } \\
\text { suara }\end{array}$ & Baik & 1 \\
\hline 14 & Jam dinding & Baik & 3 \\
\hline
\end{tabular}

Sumber Data : SDN Galang Bulan tahun 2011

\section{PENENTUAN SUMBER DATA}

\section{a) Jenis Data}

Ditinjau dari jenisnya menurut Suharsimi Arikunto,data dapat dikatagorikan kedalam :

1) Data kualitatif adalah data yang dinyatakan dalam bentuk kata, kalimat dan gambar, biasanya berhubungan dengan nilai. Misalnya baik-buruk, tinggi-rendah, dan sebagainya.

2) Data kuantitatif adalah data yang berwujud angka-angka hasil perhitungan ataupun data yang diperoleh dengan mengubah data kualitatif yang dikuantitatifkan .Dengan mengetahui jenis data,maka dapat ditentukan tehnik analisanya,apakah menggunakan analisa statistik atau non statistik (Arikunto, 2006: 245)

Berdasarkan pendapat diatas, maka jenis data dalam penelitian ini adalah kuantitatif.

\section{b) Sumber Data}

"Yang dimaksud dengan sumber data dalam penelitian ini adalah subjek dari mana data dapat diperoleh (Arikunto, 2006: 129 ) Dalam penelitian ini, sumber data dapat diklasifikasikan menjadi 2 ( dua ) yaitu data primer dan data sekunder, dimana data primer yaitu data yang dikumpulkan oleh peneliti (atau petugas-petugasnya ) dari sumber pertamanya (Suryabrata, 2007: 93 ). Sedangkan data sekunder merupakan data yang diperoleh dari sumber tertulis atau dokumen-dokumen, daftar nilai, dan sebagainya “(Arikunto, 2006: 129)

Dengan demikian yang menjadi data primer dalam penelitian ini adalah data yang diperoleh dari angket dan observasi, sedangkan sumber skundernya 
54 CIVICUS I Pendidikan Pancasila dan Kewarganegaraan data yang diperoleh dari dokumentasi. Adapun sumber data yang akan di gunakan sebagai subyek dalam penelitian ini adalah siswa kelas IV. Hal ini sesuai dengan ketentuan yang mengakatan " Jika jumlah subyeknya besar atau lebih dari 100 maka yang diambil sebagai subyeknya antara 20-25\% atau 10-15\% tergantu dari kemampuan peneliti dalam melakukan penelitian sedangkan jika jumlah subyeknyan kecil atau kurang dari 100 sebaiknya diambil semuanya dan dinamakan sebagai penelitian populasi (Arikunto, 2006:134).

\section{DEFINISI OPERASIONAL VARIABEL}

Definisi operasional variabel sebagai berikut:

a) Model pembelajaran Problem based instruction adalh pendekatan yang menggunakan pendekatan pembelajaran siswa pada masalah kehidupan nyata. Problem based instruction dikembangkan untuk membantu siswa mengembangkan kemampuan berpikir, pemecahan masalah dan keterampilan intelektual, belajar berbagai peran, melalui pengalaman belajar dalam kehidupan nyata.

b) Hasil Belajar siswa adalah hasil yang diperoleh siswa dalam proses pembelajaran berdasarkan ranah kognitif, afektif dan psikomotorik.

\section{INSTRUMEN PENELITIAN}

Adapun instrument yang di gunakan dalam penelitian ini adalah:

\section{a) Metode Tes}

Metode tes adalah alat pengumpulan data yang berbentuk suruhan-suruhan yang harus dilaksanakan oleh subyek penelitian (Surakhman, 2008:35). Sedangkan ahli lain mengatakan suatu cara untuk mengadakan penilaian suatu subyek atau obyek-obyek tertentu untuk mendapatkan data secara tepat dan cepat (Arikunto, 2006:56).

Dalam penelitian ini menggunakan metode test dengan maksud mengetahui hasil belajar siswa dengan penerapan Problem Based Instruduction (PBI) siswa kelas IV di SDN Galang Bulan Desa Jelantik Kec.Jongkat Kab. Lombok Tengah tahun pelajaran 2011-2012.

\section{b) Metode Dokumentasi}

Metode dokumentasi adalah suatu metode pengumpulan data dan sumber-sumber yang tertulis baik berupa surat, foto, gambar, grafik maupun keterangan-keterangan lainnya yang tertulis. Dalam penelitian ini data yang dikumpulkan melalui metode dokumentasi adalah data mengenai nama dan jumlah kelas IV di SDN 2 Galang Bulan Desa Jelantik Kec.Jongkat Kab. Lombok Tengah tahun pelajaran 2011-2011.

\section{Berikut kisi-kisi soal mata pelajaran PPKN siswa} kelas IV

\begin{tabular}{|c|c|c|c|c|}
\hline $\begin{array}{c}\text { Standar } \\
\text { kompetensi }\end{array}$ & $\begin{array}{l}\text { Kompeten } \\
\text { si dasar }\end{array}$ & Indikator & $\begin{array}{l}\text { No. } \\
\text { Butir }\end{array}$ & Jml Butir \\
\hline $\begin{array}{l}\text { Memahami } \\
\text { Pemerintahan } \\
\text { seda dan } \\
\text { pemerintahan } \\
\text { kecamatan }\end{array}$ & $\begin{array}{l}\text { Memahami } \\
\text { lembaga - } \\
\text { lembaga } \\
\text { dalam } \\
\text { susunan } \\
\text { pemerintaha } \\
\text { n desa dan } \\
\text { kecamatan }\end{array}$ & $\begin{array}{l}\text { Lembaga } \\
\text { pemerinta } \\
\text { han desa } \\
\text { dan } \\
\text { kecamatan } \\
\\
\text { Struktur } \\
\text { organisai } \\
\text { pemerinta }\end{array}$ & $\begin{array}{l}1,2,3,4 \\
, 5,, 6,7\end{array}$ & 7 \\
\hline
\end{tabular}

\begin{tabular}{|c|c|c|c|c|}
\hline & $\begin{array}{l}2 \\
. \text { Menggamb } \\
\text { arkan } \\
\text { struktur } \\
\text { organisasi } \\
\text { desa dan } \\
\text { kecamatan }\end{array}$ & $\begin{array}{l}\text { han dan } \\
\text { kecamatan }\end{array}$ & $\begin{array}{l}11,12,1 \\
3,14\end{array}$ & \\
\hline $\begin{array}{l}2 . \\
\text { Memaham } \\
\text { sistem } \\
\text { pemerintahan } \\
\text { dan } \\
\text { kabupaten, } \\
\text { kota dan } \\
\text { propinsi }\end{array}$ & $\begin{array}{l}\text { Mengenal } \\
\text { lembaga- } \\
\text { lembaga } \\
\text { dalam } \\
\text { susunan } \\
\text { pemerinta } \\
\text { han } \\
\text { kabupaten } \\
\text {, kota dan } \\
\text { propinsi } \\
\end{array}$ & $\begin{array}{l}\text { Lembaga } \\
\text { pemerinta } \\
\text { han } \\
\text { kabupaten } \\
\text { /Kota dan } \\
\text { propinsi }\end{array}$ & $\begin{array}{c}15,16,1 \\
7,18,19 \\
, 20,\end{array}$ & 6 \\
\hline \multicolumn{3}{|c|}{ Jumlah } & 20 & 20 \\
\hline
\end{tabular}

\section{Analisis Data}

Analisa data merupakan usaha ( proses ) memilih, memilah, membuang, dan menggolongkan data untuk menjawab dua permasalahan pokok, yaitu:(1) tema apa yang ditemukan pada data-data ini dan ( 2 ) seberapa jauh data-data ini dapat menyokong tema tersebut. (Basrowi, 2007: 111).

Penentuan model analisa yang dipilih harus benar-benar sesuai dengan jenis-jenis data yang diperoleh, Data kuantitatif dapat dianalisis secara deskriptif ( prosentase, mean, median, mode, simpang baku, frekwensi, tabel, grafik, chart, dan sebagainya ). (Basrowi, 2007; 111)

Sehubungan dengan penelitian ini metode analisis data yang digunakan adalah analisis statistic dengan menggunakan rumus Uji treatment $(t)$ dengan analisis varian 2 jalur sebagai berikut:

$$
t=\frac{M d}{\sqrt{\frac{\sum X^{2} d}{N(N-1}}}
$$

Keterangan :

Md = Mean diffences (perbedaan pre test

$$
\text { dengan post test) }
$$

$\mathrm{N} \quad=$ Jumlah Subjek

$\sum \mathrm{X}^{2} \mathrm{~d}=$ Jumlah deviasi dari mean perbedaan

d.b = ditentukan dengan N-1 (Arikunto, 2006: 76)

Rumus $t$ diatas dipergunaakan untuk menganalisis hasil eksperimen dari kelompok tunggal (one-group) yang diteliti. Menurut Suaharsimi Arikunto (2006:76) rumus $\mathrm{t}$ one group dipergunakan untuk menilai hasil test awal (pre-test) dan hasil test akhir (post-test) atau menilai hasil tes sebelum dan sesudah perlakuan dari kelompok eksperimen.

Adapun langkah-langkah yang ditempuh dalam menganalisis data penelitian adalah sebagai berikut:

1) Merumuskan Hipotesis Nihil (Ho)

2) Menyusun tebel kerja

3) Memasukkan data kedalam rumus

4) Menguji signifikan nilai t

5) Menarik kesimpulan

\section{HASIL DAN PEMBAHASAN}

1. HASIL PENELITIAN

a) Deskripsi Data Penelitian 
Pada penelitian dengan judul penerapan model Pembelajaran Problem Based Instruduction (PBI) dapat meningkatkan hasil belajar siswa kelas IV di SDN 2 Galang Bulan Desa Jelantik Kec. Jonggat Kab. Lombok Tengah tahun pelajaran 2011-2012, dapat ditentukan bahwa variabel yang digunakan adalah variabel timbal balik atau saling mempengaruhi antara variabel yang satu dengan variabel yang lainnya.

Proses pengumpulan data yang dilakukan untuk mengetahui hasil masing-masing variabel, maka dilakukan studi secara seksama di lokasi penelitian baik melalui dokumentasi, dan tes.

Betolak dari permasalahan penelitian, yaitu apakah penerapan model Pembelajaran Problem Based Instruduction (PBI) dapat meningkatkan hasil belajar siswa kelas IV di SDN Galang Bulan Desa Jelantik Kec. Jonggat Kab. Lombok Tengah tahun pelajaran 20112012, maka diperlukan adanya tes terhadap para siswa baik sebelum digunakannya model pembelajaran Problem Based Instruction (PBI). Tes yang di gunakan untuk untuk mengetahui hasil belajar tersebut adalah untuk mengetahui kemampuan para siswa.

Kemampuan tersebut tentu sekali erat kaitannya dengan penggunaan metode pembelajaran. Namun perlu di ketahui bahwa masing-masing metode pembelajaran atau model pembelajaran memiliki kelebihan dan kekurangan. Hal ini menyebabkan harus adanya keterampilan guru dalam menentukan metode pembelajaran yang di gunakan harus sesuai dengan materi pelajaran yang disampaikan. Jika metode pembelajaran yang digunakan tidak relevan dengan metode pembelajaran yang di gunakan maka hasil yang dicapai juga cendrung tidak sesuai dengan harapan.

Model pembelajatan Problem Based Instruction (PBI) sebagai salah satu metode memiliki karakteristik untuk menyelesaikan permasalahan yang di hadapi oleh masing-masing siswa. Dalam penyajian data berikut akan penulis sajikan berbagai data mengenai data-data dari sampel yang diteliti,

Tabel Data Hasil Belajar Bahasa PPPKN Yang Diajar Tanpa menggunakan model Pembelajaran Problem Based Instruduction (PBI) pada siswa kelas IV di SDN Galang Bulan Desa Jelantik Kec. Jonggat Kab. Lombok Tengah tahun pelajaran 2011-2012

\begin{tabular}{|c|c|c|c|c|}
\hline \multirow[b]{2}{*}{ No } & \multirow[b]{2}{*}{ Nama Siswa } & \multirow{2}{*}{$\begin{array}{c}\text { Jenis } \\
\text { Kelamin }\end{array}$} & \multicolumn{2}{|c|}{ Nilai } \\
\hline & & & Pre - test & $\begin{array}{c}\text { Pos - } \\
\text { test }\end{array}$ \\
\hline 1 & 2 & 3 & 4 & 5 \\
\hline 1 & Abdul Hamid & $\mathrm{L}$ & 50 & 55 \\
\hline 2 & Agam Anantama & $\mathrm{P}$ & 55 & 60 \\
\hline 3 & Imran Syamsuri & $\mathrm{P}$ & 60 & 65 \\
\hline 4 & Mustakim & $\mathrm{P}$ & 55 & 60 \\
\hline 5 & Arjuna & $\mathrm{P}$ & 55 & 65 \\
\hline 6 & Faisal A. Rahim & $\mathrm{P}$ & 55 & 68 \\
\hline 7 & Abdul Fatah & $\mathrm{P}$ & 60 & 68 \\
\hline 8 & Hamzah & $\mathrm{P}$ & 55 & 60 \\
\hline 9 & Hamdi & $\mathrm{L}$ & 60 & 65 \\
\hline 10 & Ahmad Gazali & $\mathrm{P}$ & 55 & 65 \\
\hline 11 & Indra Bakti & $\mathrm{P}$ & 65 & 70 \\
\hline (1) & (2) & (3) & (4) & (5) \\
\hline 12 & Hamdan & $\mathrm{P}$ & 65 & 70 \\
\hline 13 & Sahri & $\mathrm{P}$ & 55 & 60 \\
\hline 14 & Adawiyah & $\mathrm{P}$ & 55 & 65 \\
\hline 15 & Ainun Nikmah & $\mathrm{P}$ & 65 & 70 \\
\hline 16 & Marlina & $\mathrm{P}$ & 55 & 65 \\
\hline 17 & Masa & $\mathrm{P}$ & 60 & 65 \\
\hline
\end{tabular}

\begin{tabular}{|c|c|c|c|c|}
\hline & Khairiyah & & & \\
\hline 18 & Rauhuniati & $\mathrm{L}$ & 55 & 60 \\
\hline 19 & Khairani & $\mathrm{L}$ & 65 & 70 \\
\hline 20 & Nani Julianti & $\mathrm{L}$ & 55 & 60 \\
\hline 21 & Nina Wahyu & $\mathrm{L}$ & 65 & 70 \\
\hline 22 & Nur Ayeni Rusti & $\mathrm{P}$ & 55 & 65 \\
\hline 23 & Nuraini JH & $\mathrm{P}$ & 65 & 70 \\
\hline 24 & Nuraini M. Yusuf & $\mathrm{P}$ & 55 & 60 \\
\hline 25 & $\begin{array}{l}\text { Nurhidayah } \\
\text { Ibrahim }\end{array}$ & $\mathrm{P}$ & 60 & 65 \\
\hline 26 & Nursarinah & $\mathrm{P}$ & 55 & 67 \\
\hline 27 & Nurul Hardiyanti & $\mathrm{P}$ & 65 & 70 \\
\hline 28 & Nurul Hikmah & $\mathrm{P}$ & 65 & 70 \\
\hline 29 & Nurwahidah & $\mathrm{P}$ & 55 & 60 \\
\hline 30 & Nurwahyuni & $\mathrm{L}$ & 65 & 70 \\
\hline \multicolumn{3}{|c|}{ Jumlah } & 1760 & 1953 \\
\hline \multicolumn{3}{|c|}{ Rata-Rata } & 58,66 & 65,1 \\
\hline
\end{tabular}

Hasil belajar siswa yang tidak menggunakan metode pembelajaran problem based indtruction tersebut akan dibandingkan dengan hasil belajar siswa yang di ajarkan dengan menggunakan metode pembelajaran problem based instruction. Hal ini diperlukan untuk mengetahui peningkatan hasil belajar siswa kelas IV SDN Galang Bulan setelah di ajarkan dengan menggunakan metode pembelajaran problem based instruction. Adapaun hasil belajar siswa yang diajarkan dengan menggunakan metode pembelajaran problem based instruction adalah sebagai berikut

Tabel Data Hasil Belajar PPPKN Yang Diajar Dengan menggunakan model Pembelajaran Problem Based Instruduction (PBI) pada siswa kelas IV di SDN Galang Bulan Desa Jelantik Kec. Jonggat Kab. Lombok Tengah tahun pelajaran 2011-2012

\begin{tabular}{|c|c|c|c|c|}
\hline \multirow[b]{2}{*}{ No } & \multirow[b]{2}{*}{ Nama Siswa } & \multirow[b]{2}{*}{$\begin{array}{c}\text { Jenis } \\
\text { Kela } \\
\text { min }\end{array}$} & \multicolumn{2}{|c|}{ Nilai } \\
\hline & & & $\begin{array}{c}\text { Pr } \\
\text { e } \\
- \\
\text { Te } \\
\text { st }\end{array}$ & $\begin{array}{c}\text { P } \\
\text { os } \\
- \\
\text { Te } \\
\text { st }\end{array}$ \\
\hline 1 & Abdul Hamid & $\mathrm{L}$ & 55 & 63 \\
\hline 2 & Agam Anantama & $\mathrm{L}$ & 60 & 65 \\
\hline 3 & Imran Syamsuri & $\mathrm{L}$ & 65 & 70 \\
\hline 4 & Mustakim & $\mathrm{L}$ & 60 & 65 \\
\hline 5 & Arjuna & $\mathrm{L}$ & 65 & 71 \\
\hline 6 & Faisal A. Rahim & $\mathrm{L}$ & 70 & 75 \\
\hline 7 & Abdul Fatah & $\mathrm{L}$ & 70 & 73 \\
\hline 8 & Hamzah & $\mathrm{L}$ & 60 & 64 \\
\hline 9 & Hamdi & $\mathrm{L}$ & 65 & 72 \\
\hline 10 & Ahmad Gazali & $\mathrm{L}$ & 60 & 73 \\
\hline 11 & Indra Bakti & $\mathrm{L}$ & 65 & 75 \\
\hline 12 & Hamdan & $\mathrm{L}$ & 70 & 74 \\
\hline 13 & Sahri & $\mathrm{L}$ & 60 & 68 \\
\hline 14 & Adawiyah & $\mathrm{P}$ & 65 & 72 \\
\hline 15 & Ainun Nikmah & $\mathrm{P}$ & 70 & 77 \\
\hline 16 & Marlina & $\mathrm{P}$ & 65 & 71 \\
\hline 17 & $\begin{array}{ll}\text { Masa } & \text { atul } \\
\text { Khairiyah } & \end{array}$ & $\mathrm{P}$ & 60 & 70 \\
\hline 18 & Rauhuniati & $\mathrm{P}$ & 60 & 69 \\
\hline 19 & Khairani & $\mathrm{P}$ & 65 & 75 \\
\hline 20 & Nani Julianti & $\mathrm{P}$ & 60 & 69 \\
\hline 21 & Nina Wahyu & $\mathrm{P}$ & 70 & 75 \\
\hline 22 & Nur Ayeni Rusti & $\mathrm{P}$ & 65 & 73 \\
\hline 23 & Nuraini JH & $\mathrm{P}$ & 70 & 75 \\
\hline 24 & Nuraini M. Yususf & $\mathrm{P}$ & 55 & 65 \\
\hline 25 & $\begin{array}{l}\text { Nurhidayah } \\
\text { Ibrahim }\end{array}$ & $\mathrm{P}$ & 67 & 72 \\
\hline 26 & Nursarinah & $\mathrm{P}$ & 67 & 71 \\
\hline 27 & Nurul Hardiyanti & $\mathrm{P}$ & 70 & 75 \\
\hline 28 & Nurul Hikmah & $\mathrm{P}$ & 65 & 75 \\
\hline 29 & Nurwahidah & $\mathrm{P}$ & 55 & 68 \\
\hline 30 & Nurwahyuni & $\mathrm{P}$ & 70 & 75 \\
\hline & Jumlah & & 19 & 21 \\
\hline
\end{tabular}




\begin{tabular}{|c|c|c|}
\hline & 24 & 35 \\
\hline Rata-Rata & 64 & 71, \\
&, 13 & 16 \\
\hline
\end{tabular}

\section{b) Pengujian Hipotesis}

Adapun langkah-langkah yang ditempuh dalam penyajian hipotesis adalah Sebagai berikut :

1. Merumuskan hipotesis nol (Ho)

Untuk keperluan perhitungan analisis statistik, maka hipotesis alternatif (Ha) yang diajukan pada bab I yang berbunyi: penerapan model Pembelajaran Problem Based Instruduction (PBI) dapat meningkatkan hasil belajar siswa kelas IV di SDN Galang Bulan Desa Jelantik Kec. Jonggat Kab. Lombok Tengah tahun pelajaran 2011-2012, maka perlu di ubah terlebih dahulu ke dalam sebuah hipotesis nol (Ho) sehingga berbunyi: "penerapan model Pembelajaran Problem Based Instruduction (PBI) dapat meningkatkan hasil belajar siswa kelas IV di SDN Galang Bulan Desa Jelantik Kec. Jonggat Kab. Lombok Tengah tahun pelajaran 2011-2012.

2. Menyusun Tabel Kerja.

Berdasarkan data pada tabel 4.5 dan tabel 4.6 di atas, maka dapat di buat tabel kerja untuk mengetahui penerapan model Pembelajaran Problem Based Instruduction (PBI) pada siswa kelas IV di SDN Galang Bulan Desa Jelantik Kec. Jonggat Kab. Lombok Tengah tahun pelajaran 2011-2012. Adapun tabel kerja tersebut adalah sebagai sebagai berikut :

Tabel Data Perbandingan Hasil Belajar PPPKN Yang Diajar Dengan Menggunakan model Pembelajaran Problem Based Instruduction (PBI) pada siswa kelas IV di SDN Galang Bulan Desa Jelantik Kec. Jonggat Kab. Lombok Tengah tahun pelajaran 2011-2012

\begin{tabular}{|c|c|c|c|c|c|}
\hline \multirow[b]{2}{*}{$\begin{array}{l}\mathbf{N} \\
\mathbf{o}\end{array}$} & \multirow[b]{2}{*}{ Nama Siswa } & \multirow[b]{2}{*}{$\begin{array}{l}\text { Jenis } \\
\text { Kela } \\
\text { min }\end{array}$} & \multicolumn{3}{|c|}{ Nilai } \\
\hline & & & $\begin{array}{l}\text { Sesud } \\
\text { ah }\end{array}$ & $\begin{array}{c}\text { Sebel } \\
\text { um }\end{array}$ & $\begin{array}{c}\text { Nilai } \\
\text { Perbed } \\
\text { aan }\end{array}$ \\
\hline 1 & Abdul Hamid & $\mathrm{L}$ & 63 & 55 & 8 \\
\hline 2 & Agam Anantama & $\mathrm{L}$ & 65 & 60 & 5 \\
\hline 3 & Imran Syamsuri & $\mathrm{L}$ & 70 & 65 & 5 \\
\hline 4 & Mustakim & $\mathrm{L}$ & 65 & 60 & 5 \\
\hline 5 & Arjuna & $\mathrm{L}$ & 71 & 65 & 6 \\
\hline 6 & Faisal A. Rahim & $\mathrm{L}$ & 75 & 68 & 7 \\
\hline 7 & Abdul Fatah & $\mathrm{L}$ & 73 & 68 & 5 \\
\hline 8 & Hamzah & $\mathrm{L}$ & 64 & 60 & 4 \\
\hline 9 & Hamdi & $\mathrm{L}$ & 72 & 65 & 7 \\
\hline 10 & Ahmad Gazali & $\mathrm{L}$ & 73 & 65 & 8 \\
\hline 11 & Indra Bakti & $\mathrm{L}$ & 75 & 70 & 5 \\
\hline 12 & Hamdan & $\mathrm{L}$ & 74 & 70 & 4 \\
\hline 13 & Sahri & $\mathrm{L}$ & 68 & 60 & 8 \\
\hline 14 & Adawiyah & $\mathrm{P}$ & 72 & 65 & 7 \\
\hline 15 & Ainun Nikmah & $\mathrm{P}$ & 77 & 70 & 7 \\
\hline 16 & Marlina & $\mathrm{P}$ & 71 & 65 & 6 \\
\hline 17 & Khairiyah & $\mathrm{P}$ & 70 & 65 & 5 \\
\hline 18 & Rauhuniati & $\mathrm{P}$ & 69 & 60 & 9 \\
\hline 19 & Khairani & $\mathrm{P}$ & 75 & 70 & 5 \\
\hline 20 & Nani Julianti & $\mathrm{P}$ & 69 & 60 & 9 \\
\hline 21 & Nina Wahyu & $\mathrm{P}$ & 75 & 70 & 5 \\
\hline 22 & Nur Ayeni Rusti & $\mathrm{P}$ & 73 & 65 & 8 \\
\hline 23 & Nuraini JH & $\mathrm{P}$ & 75 & 70 & 5 \\
\hline 24 & $\begin{array}{ll}\text { Nuraini } & \text { M. } \\
\text { Yususf } & \\
\end{array}$ & $\mathrm{P}$ & 65 & 60 & 5 \\
\hline 25 & Nurhidayah & $\mathrm{P}$ & 72 & 65 & 7 \\
\hline 26 & Nursarinah & $\mathrm{P}$ & 71 & 67 & 4 \\
\hline 27 & $\begin{array}{l}\text { Nurul } \\
\text { Hardiyanti }\end{array}$ & $\mathrm{P}$ & 75 & 70 & 5 \\
\hline 28 & Nurul Hikmah & $\mathrm{P}$ & 75 & 70 & 5 \\
\hline 29 & Jumaini & $\mathrm{P}$ & 68 & 60 & 8 \\
\hline 30 & Nurwahyuni & $\mathrm{P}$ & 75 & 70 & 5 \\
\hline
\end{tabular}

\section{\begin{tabular}{|c|}
\hline Jumlah \\
\hline Rata-rata \\
\hline
\end{tabular} 2135 1953 182 6,06 \\ Tabel Nilai $\Sigma X^{2}$ d Pada Siswa Kelas IV di SDN Galang Bulan}

\begin{tabular}{|c|c|c|c|c|}
\hline $\begin{array}{l}\mathbf{N} \\
\mathbf{o}\end{array}$ & Nama Siswa & $\mathbf{D}$ & $\begin{array}{c}\mathbf{X}_{d}(\mathbf{d}- \\
\mathbf{M d}\end{array}$ & $\mathbf{X}_{d}{ }^{2}$ \\
\hline 1 & Abdul Hamid & 8 & 1,94 & 3,7636 \\
\hline 2 & Agam Anantama & 5 & $-1,06$ & 1,1236 \\
\hline 3 & Imran Syamsuri & 5 & $-1,06$ & 1,1236 \\
\hline 4 & Mustakim & 5 & $-1,06$ & 1,1236 \\
\hline 5 & Arjuna & 6 & $-0,06$ & 0,0036 \\
\hline 6 & Faisal A. Rahim & 7 & 0,94 & 0,8836 \\
\hline 7 & Abdul Fatah & 5 & $-1,06$ & 1,1236 \\
\hline 8 & Hamzah & 4 & $-2,06$ & 4,2436 \\
\hline 9 & Hamdi & 7 & 0,94 & 0,8836 \\
\hline 10 & Ahmad Gazali & 8 & 1,94 & 3,7636 \\
\hline 11 & Indra Bakti & 5 & $-1,06$ & 1,1236 \\
\hline 12 & Hamdan & 4 & $-2,06$ & 4,2436 \\
\hline 13 & Sahri & 8 & 1,94 & 3,7636 \\
\hline 14 & Adawiyah & 7 & 0,94 & 0,8836 \\
\hline 15 & Ainun Nikmah & 7 & 0,94 & 0,8836 \\
\hline 16 & Marlina & 6 & $-0,06$ & 0,0036 \\
\hline 17 & $\begin{array}{l}\text { Masa atul } \\
\text { Khairiyah }\end{array}$ & 5 & $-1,06$ & 1,1236 \\
\hline 18 & Rauhuniati & 9 & 2,94 & 8,6436 \\
\hline 19 & Khairani & 5 & $-1,06$ & 1,1236 \\
\hline 20 & Nani Julianti & 9 & 2,94 & 8,6436 \\
\hline 21 & Nina Wahyu & 5 & $-1,06$ & 1,1236 \\
\hline 22 & Nur Ayeni Rusti & 8 & 1,94 & 3,7636 \\
\hline 23 & Nuraini JH & 5 & $-1,06$ & 1,1236 \\
\hline 24 & Nuraini M. Yususf & 5 & $-1,06$ & 1,1236 \\
\hline 25 & $\begin{array}{l}\text { Nurhidayah } \\
\text { Ibrahim }\end{array}$ & 7 & 0,94 & 0,8836 \\
\hline 26 & Nursarinah & 4 & $-2,06$ & 4,2436 \\
\hline 27 & Nurul Hardiyanti & 5 & $-1,06$ & 1,1236 \\
\hline 28 & Nurul Hikmah & 5 & $-1,06$ & 1,1236 \\
\hline 29 & Nurwahidah & 8 & 1,94 & 3,7636 \\
\hline 30 & Nurwahyuni & 5 & $-1,06$ & 1,1236 \\
\hline \multicolumn{2}{|c|}{ Jumlah } & 182 & 0,2 & 67,868 \\
\hline
\end{tabular}

\section{Memasukkan data ke dalam rumus}

Adapun rumus yang digunakan untuk melakukan analisis data tentang penerapan model Pembelajaran Problem Based Instruduction (PBI) dapat meningkatkan hasil belajar siswa kelas IV di SDN Galang Bulan Desa Jelantik Kec. Jonggat Kab. Lombok Tengah tahun pelajaran 2011-2012, dengan menggunakan rumus sebagai berikut

$$
\begin{aligned}
\mathrm{Md} & =\frac{\sum d}{n}=\frac{182}{30} \\
\mathrm{t} & =\frac{M d}{\sqrt{\frac{\Sigma X^{2} d}{N(N-1)}}} \\
& =\frac{6,06}{\sqrt{\frac{67,868}{30(30-1)}}} \\
& =\frac{6,06}{\sqrt{\frac{67,868}{30(30-1)}}} \\
& =\frac{6,06}{\sqrt{\frac{67,868}{870}}}
\end{aligned}
$$




$$
\begin{aligned}
& =\frac{6,06}{\sqrt{0,07}} \\
& =\frac{6,06}{0,264} \\
& =22,97
\end{aligned}
$$

4. Menguji nilai

Dari hasil perhitungan ternyata nilai $t_{\text {hitung }}$ yang diperoleh dalam penelitian ini adalah 22, 97, sedangkan nilai $t_{\text {tabel }}$ dalam tabel dengan taraf kepercayaan $5 \%$ dan $\mathrm{N}=30$ adalah 2,423 kenyataan ini menunjukkan bahwa nilai $t_{\text {hitung }}$ yang diperoleh dalam penelitian ini lebih besar dari pada nilai $t_{\text {tabel }}$ dalam tabel, $(22,97>2,423)$ kenyataan ini menunjukkan thitung adalah signifikan. Dengan demikian berarti Ho ditolak, sedangkan Ha diterima.

5. Menarik kesimpulan

Dari hasil pengajian nilai $t_{\text {hitung }}$ di atas, dimana $t_{\text {hitung }}$ sebesar 22, 97 lebih besar dari nilai $t_{\text {tabel }}$ sebesar 2,423 dengan taraf kepercayaan 5\% maka $t_{\text {hitung }}$ dinyatakan signifikan dan hipotesis nol (Ho) ditolak atau hipotesis alternatif (Ha) diterima. Maka kesimpulan analisis dalam penelitian ini adalah: "penerapan model Pembelajaran Problem Based Instruduction (PBI) dapat meningkatkan hasil belajar siswa kelas IV di SDN Galang Bulan Desa Jelantik Kec. Jonggat Kab. Lombok Tengah tahun pelajaran 20112012.

\section{PEMBAHASAN}

Berdasarkan hasil perhitungan dengan menggunakan t-hitung diperoleh nilai t-hitung sebesar 22, 97 langkah selanjutnya adalah membandingkan nilai tersebut dengan nilai $t_{\text {tabel }}$ pada derajat kepercayaan $5 \%$, dimana diperoleh hasil sebesar 2,423 .

Setelah diketahui hasil perhitungan dengan menggunakan uji-t diperoleh hasil bahwa hasil $\mathrm{t}_{\text {hitung }}$ sebesar 22, 97 dan $\mathrm{t}_{\text {tabel }}$ sebesar 2,423. Jadi signifikan

karena $\mathrm{r}_{\text {hitung }}>\mathrm{r}_{\text {tabel }}$ maka $\mathrm{H}_{0}$ ditolak artinya hipotesis

$\mathrm{H}_{a}$ diterima. Dengan demikian, dapat disimpulkan bahwa "penerapan model Pembelajaran Problem Based Instruduction (PBI) dapat meningkatkan hasil belajar siswa kelas IV di SDN Galang Bulan Desa Jelantik Kec. Jonggat Kab. Lombok Tengah tahun pelajaran 20112012.

Secara umum hasil belajar PPKN yang diajarkan dengan menggunakan Metode problem Based Instruction. Pada mata pelajaran PPKN pada siswa kelas IV di SDN Galang Bulan dapat digolongkan cukup baik dan nilai perolehan secara klasikal cukup tinggi. Hal ini disebabkan oleh kemampuan siswa bekerja sama dengan temannya dalam belajar.

Hal ini terbukti dari nilai rata-rata yang diperoleh oleh siswa yang diajarkan dengan menggunakan Metode Problem Based Instruction. Pada mata pelajaran PPKN lebih tinggi jika dibandingkan dengan nilai rata-rata siswa yang diajarkan dengan menggunakan metode lain dimana nilai rata-rata siswa yang diajarkan dengan Penerapa Metode Problem Based Instruction. Pada mata pelajaran PPKN dapat meningkatkan hasil belajar siswa kelas IV di SDN Galang Bulan adalah sebesar 75,2 dan yang yang diajarkan dengan menggunakan metode lain (discovery) adalah sebesar 65,36.

Penggunaan metode pembelajaran yang mampu meningkatkan agar siswa menjadi lebh aktif merupakan salah satu fungsi dari keberadaan suatu metode. Metode yang memiliki relevansi dengan materi yang diajarkan adalah suatu keharusan demi mewujudkan kondisi pembelajaran yang dinamis dan inovatif.

Metode Problem Based Isntruktion merupakan metode yang mengedepankan penyelesaian masalah dengan mengacu kepada garis koordinasi yang jelas. Prinsip yang paling umum untuk diterapkan pada metode pembelajaran ini adalah adanya upaya memberikan kesempatan kepada para siswa untuk berfikr dan lebih menekankan adanya penyelesaian masalah.

Problem based instruction dirancang untuk mencapai tujuan-tujuan seperti menyelidiki, memahami dan membantu siswa menjadi pembelajar yang mandiri. Pengembangan keterampilan kerjasama di antara siswa dan saling membantu dibutuhkan dalam pelaksanaan Problem based instruction untuk menyelediki masalah secara bersama. Siswa diajarkan untuk menjadi penyelidik yang aktif sehingga membuat mereka berpikir tentang masalah dan jenis informasi yang diperlukan untuk memecahkan masalah tersebut.

Problem based instruction tidak dirancang untuk membantu guru memberikan informasi sebanyakbanyaknya kepada siswa. Siswa dilibatkan dalam pengalaman nyata dan menjadi pembelajaran yang mandiri. Pengalaman siswa yang diperoleh dari lingkungan dijadikan bahan dan materi guna memperoleh pengertian serta dapat dijadikan pedoman dan tujuan belajarnya. Problem based instruction dikembangkan untuk membantu siswa mengembangkan kemempuan berpikir, pemecahan masalah dan keterampilan intelektual (Ibrahim dan Nur 2004:7). Problem based instruction dapat dijadikan pendekatan yang efektif untuk pengajaran proses berpikir tingkat tinggi.

Pembelajaran ini membantu siswa untuk memproses informasi yang sudah jadi dalam benaknya dan menyusun pengetahuan mereka sendiri. Siswa harus mengansumsi, mengumpulkan informasi, menginterpretasi data, menginferensi, menganalisis, dan mengevaluasi. Ratumanan dan Holil (2008) berpendapat bahwa pembelajaran ini cocok untuk mengembangkan pengetahuan dasar maupun kompleks.

\section{SIMPULAN DAN SARAN}

\section{SIMPULAN}

Berdasarkan hasil perhitungan dan pembahasan dapat disimpulkan bahwa penerapan model Pembelajaran Problem Based Instruduction (PBI) dapat meningkatkan hasil belajar siswa kelas IV di SDN Galang Bulan Desa Jelantik Kec. Jonggat Kab. Lombok Tengah tahun pelajaran 2011-2012.. Hal ini terbukti dari hasil perhitungan dengan menggunakan t-hitung diperoleh nilai sebesar 22, 97 langkah selanjutnya adalah membandingkan nilai tersebut dengan nilai $\mathrm{t}_{\text {tabel }}$ pada derajat kepercayaan 5\% dan diperoleh hasil 


\section{SARAN}

Berdasarkan kesimpulan di atas maka dibuat saran-saran sebagai berikut:

1. Kepala Sekolah, diharapkan agar senantiasa memberikan motivasi dan dorongan kepada para pendidik agar senantiasa menggunakan pendekatan pembelajaran yang dapat menyebabkan siswa menjadi semakin aktif.

2. Para Pendidik, diharapkan agar pendidik senantiasa memberikan pembelajaran dengan menggunakan metode pembelajaran yang mampu mendorong adanya kemampuan siswa dalam belajar lebih baik.

3. Para peserta didik, diharapkan agar senantiasa aktif dan kreatif serta bersemangat untuk mengikuti pembelajaran yang dilaksanakan.

Peneliti lain, diharapkan agar melakukan kajian secara mendalam tentang perbedaan prestasi belajar antara yang diajar dengan menggunakan metode yang variatif.

\section{DAFTAR RUJUKAN}

Abbas. 2007.Metode Pembelajaran Inovatif. Surabaya: SIC. Adinegoro. 1975. Metodologi Penelitian Pendidikan. Jakarta: PT Reneka Cepta.

Aunurrahman. 2010. Penelitian Lanjutan. Jakarta: Diknas.

Diknas. 2003. Kamus Besar Bahasa Indonesia . Jakarta: Balai Pustaka.

Hadi Haryono. 2005. Metode Penelitian Aplikatif. Jakarta: Balai Pustaka.

Ibrahim. 2004. Perencanaan Pembelajaran. Jakarta: PT. Gramedia Persada.

Nana Sudjana. 2004. Pengembangan Kognitif. Bandung: PT. Rosdakarya.

Nurdiana. 2004. Metode Pembelajaran. Bandung: CV. Wacana Cipta.

Nurkencana. 1990. Metode Penelitian Aplikatif. Bandung: CV. Wacana Prima.

Rahmat. 2001. Metode Penelitian Kebidanan. Jakarta: PR. Gramedia Persada.

Ratumanan. 2008. Metode Pembelajaran. Yogyakarta: PT. Genta Press.

Ridwan. 2005. Metode Penelitian Pendidikan. Jakarta: CV. Rineka Cipta.

Riyanto Yatim. 2001. Metode Penelitian Pendidikan. Surabaya: Penerbit SIC.

Roestiyah. 2001. Strategi Belajar Mengajar. Jakarta: Rineka Cipta.

Slameto. 2003. Belajar dan Faktor-Faktor Yang Mempengaruhinya. Jakarta: Rineka Cipta.

Sudrajat.2006. Kompetensi Pembelajaran. Bandung: CV. Rosdakarya. 2006.

Sugiyono. 2006. Metode Penelitian Administrasi. Bandung: Alfabeta.

Suharsimi Arikunto. 2002. Prosedur Penelitian Suatu Pendekatan Praktek. Jakarta: Rineka Cipta.

_ 2006. Prosedur Penelitian Suatu Pendekatan Praktek. Jakarta: Rineka Cipta.

Sumadi Suryasubrata. 2007. Metode Penelitian Praktis. Jakarta. LP3ES.

Sumarsono S. 2004. Pendidikan Kewarganegaraan. Jakarta: Diknas.

Sutardi dkk. 2001. Perencanaan Pembelajaran. Jakarta:

LP3ES.

Sutomo. 2004. Aktivitas Belajar Mengajar. Yogyakarta: PT.

Genta Press.

Trianto. 2010. Pembelajaran Inovatif. Jakarta: PT. Rosda Karya.

UU RI. 2005. Sisdiknas. Bandung: Fokusmed 